\title{
Osteoporotic hip fractures: Bisphosphonates sales and observed turning point in trend. A population-based retrospective study
}

\author{
Sandra Maria Alves a,b,*, Theodoros Economou ${ }^{c}$, Carla Oliveira ${ }^{\mathrm{a}, \mathrm{d}, \mathrm{e}}$, Ana Isabel Ribeiro ${ }^{\mathrm{a}, \mathrm{d}, \mathrm{e}}$, Nuno Neves ${ }^{\mathrm{a}, \mathrm{f}}$, \\ Enrique Goméz-Barrena ${ }^{g}$, Maria Fátima Pina ${ }^{\text {a,d,e }}$ \\ ${ }^{a}$ Rua do Campo Alegre, 823, 4150-180 Porto, INEB, Instituto de Engenharia Biomédica, Portugal \\ ${ }^{\text {b } R u a ~ V a l e n t e ~ P e r f e i t o, ~ 322, ~ 4400-330 ~ V l a ~ N o v a ~ d e ~ G a i a, ~ E S T S P / I P P, ~ E s c o l a ~ S u p e r i o r ~ d e ~ T e c n o l o g i a ~ d a ~ S a u ́ d e ~ d o ~ P o r t o, ~ P o r t u g a l ~}$ \\ c North Park Road, Exeter, EX1 3HR, College of Engineering, Mathematics and Physical Sciences, University of Exeter, United Kingdom \\ d Rua das Taipas 135, 4050-600, Porto, ISPUP, Instituto de Saúde Pública da Universidade do Porto, Portugal \\ e Al. Prof. Hernâni Monteiro, 4200 - 319 Porto, Departamento de Epidemiologia Clínica, Medicina Preditiva e Saúde Pública, Faculdade de Medicina da Universidade do Porto, Portugal \\ ${ }^{\mathrm{f}}$ Alameda Prof. Hernâni Monteiro, 4200-319 Porto, Serviço de Ortopedia, Hospital São João, Portugal \\ g Po Castellana 261, Madrid 28046, Servicio de Cirugía Ortopédica y Traumatología, Hospital La Paz-IdiPAZ, Universidad Autónoma de Madrid, Spain
}

\section{A R T I C L E I N F O}

Article history:

Received 16 October 2012

Revised 3 December 2012

Accepted 17 December 2012

Available online 27 December 2012

Edited by: Felicia Cosman

\section{Keywords:}

Bisphosphonates

Osteoporosis

Hip fractures

Anti-osteoporotic medication

Population studies

\begin{abstract}
A B S T R A C T
The aim is to examine the temporal trends of hip fracture incidence in Portugal by sex and age groups, and explore the relation with anti-osteoporotic medication.

From the National Hospital Discharge Database, we selected from 1st January 2000 to 31st December 2008, 77,083 hospital admissions ( $77.4 \%$ women) caused by osteoporotic hip fractures (low energy, patients over 49 years-age), with diagnosis codes 820.x of ICD 9-CM. The 2001 Portuguese population was used as standard to calculate direct age-standardized incidence rates (ASIR) (100,000 inhabitants). Generalized additive and linear models were used to evaluate and quantify temporal trends of age specific rates (AR), by sex.

We identified 2003 as a turning point in the trend of ASIR of hip fractures in women. After 2003, the ASIR in women decreased on average by 10.3 cases $/ 100,000$ inhabitants, $95 \% \mathrm{CI}(-15.7$ to -4.8$)$, per 100,000 anti-osteoporotic medication packages sold. For women aged 65-69 and 75-79 we identified the same turning point. However, for women aged over 80, the year 2004 marked a change in the trend, from an increase to a decrease. Among the population aged 70-74 a linear decrease of incidence rate (95\% CI) was observed in both sexes, higher for women: $-28.0 \%(-36.2$ to -19.5$)$ change vs $-18.8 \%$, $(-32.6$ to -2.3$)$.

The abrupt turning point in the trend of ASIR of hip fractures in women is compatible with an intervention, such as a medication. The trends were different according to gender and age group, but compatible with the pattern of bisphosphonates sales.
\end{abstract}

(C) 2013 Elsevier Inc. All rights reserved.

\section{Introduction}

Identifying and understanding trends of hip fracture incidence is important, not only as a way for planning future medical resources and treating patients but also in planning effective preventive measures [1]. Costs related to hip fractures are not only restricted to hospitalization but also to the long recovery time and assistance that these patients require $[2,3]$. Public health interventions can be taken using knowledge gathered from epidemiologic studies using secondary data. These studies can provide valuable information with the use of reliable data on a national basis $[4,5]$.

\footnotetext{
* Corresponding author at: Rua do Campo Alegre, 823, 4150-180 Porto, INEB, Instituto de Engenharia Biomédica, Portugal. Fax: + 351226094567.

E-mail addresses: smfalves@gmail.com (S.M. Alves), t.economou@exeter.ac.uk (T. Economou), carlaoliveir@gmail.com (C. Oliveira),

ana.isabel.correia.ribeiro@gmail.com (A.I. Ribeiro),nsmneves@gmail.com (N. Neves), egomezbarrena@gmail.com (E. Goméz-Barrena),fpina@ineb.up.pt (M.F. Pina).
}

The bone quality impairment is associated to aging and elevates the risk of osteoporotic fractures, particularly in post-menopausal women. Furthermore, an excessive pathologic decrease in bone strength can be prevented either by the use of medicaments or by changing activity and nutritional behaviour [6]. Osteoporotic hip fractures are more common among women over the age of 49 years and grows exponentially with aging. With the increase of life expectancy the range of population at risk is considerable, enhancing the need to analyze trends by age groups. In 2008, life expectancy at age 65 in the European Union (27 member states) was 17.2 and 20.7 years for males and females respectively [7]. In Portugal, the same indicator with data from 2009 to 2011 was 16.9 and 20.2 respectively (last available data) [7,8]. Moreover, the elderly form the fastest growing age group in most western countries thus aggravating the burden of osteoporosis.

In Portugal there are no national studies addressing the trend of hip fractures. However, internationally several studies have been conducted reporting trends of age-standardized incidence rates of hip fractures [1]. Nevertheless the results are not consensual: increasing, decreasing and 
stable trends have been reported, which may reflect different stages in the epidemic curve. The results regarding the shape of the trends as well an existing pattern in men have also differ. Studies in Finland [9] and Australia $[10,11]$ have reported rates of hip fractures compatible with a non-linear trend. However in Finland the decrease pattern was observed in both genders, whereas in Australia only women presented a decreasing pattern. Rates presenting linear decreases have been reported by studies in Belgium [12], Denmark [13], Canada [14], United States [15] for both genders and Spain just for women [16]. Unique causes are impossible to assess, nevertheless studies have pointed out different plausible reasons, according to their results, namely medication for osteoporosis $[10,11,16]$ or other interventions $[13,14]$.

It is important to explore time trends of age-standardized incidence rates of hip fractures although they may hide different underlying trends by age groups thus leading to incorrect conclusions. And since hip fractures affect a wide range of ages, these studies may help uncover unequal patterns and meaningful associations with the preventive procedures undertaken by different countries.

The aim of this work is to examine the temporal trends of hip fracture incidence in Portugal by sex and age group, and explore its relation with anti-osteoporotic medication.

\section{Materials and methods}

\section{Study area}

The study area was Continental Portugal with a population of 10,135,309 inhabitants in 2008. In 2000 there were 3,298,922 inhabitants aged 50 years or over, increasing by $11.9 \%$ in $2008(n=3,691,104)$ [8], in contrast with a decrease of $-0.6 \%$ in the population aged under 50 in the same period.

\section{Data}

Population data was the annual official estimates, per sex and 5-year age groups, except for 2001, which was a census year.

We used data from the National Hospital Discharge Register (NHDR). The use of this administrative database is mandatory since 1997 in all Portuguese public hospitals, and compiles information on all discharges such as gender, age, admission and discharge date; first cause of admission (and up to 19 secondary causes) coded according to the International Classification of Diseases, version 9, Clinical Modification (ICD9-CM); main diagnosis (and up to 19 secondary diagnoses), also coded according to the ICD9-CM; clinical interventions (up to 20); surgical interventions; hospital providing the care; outcome (deceased, discharge to home, discharge to another hospital); length of stay (LOS) and patient's place of residence.

In Portugal, access to the national health-care system is free and universal and due to the high costs involved, hip fractures are primarily treated in public hospitals. Therefore hip fractures are highly documented and the NHDR records the total number of admissions with a diagnosis of hip fracture nationwide.

The quality of the NHDR is accessed regularly by both internal (hospitals) and external (ACSS - Central Administration of the National System) auditors [17].
We selected all discharges from 1st January 2000 to 31st December 2008 of individuals aged 50 years or over, with a diagnosis of hip fracture (codes ICD9-CM 820.x) caused by a low or moderate trauma. We excluded cases of bone cancer, readmissions for orthopedic after-care or complications in surgical and medical care (codes ICD9-CM: 170.x, 171.x, V54.x, 996.4), the exclusion expression was applied to all 20 fields containing diagnosis, and represented $0.8 \%$ of the cases. To account for misclassification on the diagnosis field other actions were taken, namely revisions were excluded based on procedures codes (81.53 Revision of hip replacement, not otherwise specified) representing a total of $0.08 \%$ of the cases. In addition we also excluded cases with length of stay inferior to 5 days, that did not went to a surgery and that were transferred to another hospital, because the first hospitalization could be just to stabilize the patient, these represent $1.1 \%$ of the cases.

In Portugal it is not possible to have database linkage between NHDR and prescriptions so the data on medication was only available for the entire population, and therefore it was not possible to access sales desegregated by sex and age groups, or have the number of patients treated. Data was provided by the National Authority of Medicines and Health Products (INFARMED). We analyzed, on a national level, the number of anti-osteoporotic medication packages sold from 2000 to 2008 through prescriptions made in the National Health System (NHS). We used the total number of anti-osteoporotic medication for the entire population to explain the trend of hip fractures in women, based on our preliminary results that showed no increasing or decreasing trends in ASIR for men. The stable incidence rates of hip fractures among men is compatible with the low prescription of anti-osteoporotic medication for men identified in other countries [12] and information contained in Portuguese national guidelines $[18,19]$ which focus the prevention of osteoporosis in women. The medications analyzed were those indicated as agents that can act on the inhibition of bone loss or promote directly bone formation $[20,21]$ with a high evidence level of reducing the risk of a hip fracture: bisphosphonates, calcitonin, hormonal replacement therapy (HRT), Strontium ranelate and Selective Estrogen Receptor Modulators (Reloxifene) as well as vitamin D (recommended to be prescribed in association with the medications mentioned [19]).

We used the Portuguese population from the 2001 census, available from the Statistics Portugal (Instituto Nacional de Estatística INE) as the standard for calculating the direct age-standardized incidence rates (ASIR) per 100,000 inhabitants by gender.

We calculated age-specific rates (AR) by gender, using population counts in the census year of 2001 and official estimates for all the other years. Five-year age groups were used from 50 to 84 years of age and a wider group comprising all patients older than 84 .

In addition, we calculated the $95 \%$ Confidence Intervals (95\% CI) for each rate according to the methods described in Morris and Gardner (2000) [22].

\section{Statistical analysis}

We used Generalized Additive Models (GAMs) to investigate changes in the trends of incidence rates. These models are flexible as they incorporate a non-parametric component that is implemented using spline functions (smoothers) and can reveal possible non-linearities in the

Table 1

Summary of statistics of in-patients characteristics in portugal (2000-2008).

\begin{tabular}{|c|c|c|c|c|c|c|c|c|c|}
\hline Variable & 2000 & 2001 & 2002 & 2003 & 2004 & 2005 & 2006 & 2007 & 2008 \\
\hline \multicolumn{10}{|l|}{ Men } \\
\hline No. of admissions & 1752 & 1947 & 1780 & 1989 & 1981 & 1961 & 2069 & 1913 & 2027 \\
\hline Age (mean; (SD)) & $77.6(10.02)$ & $77.4(10.03)$ & $78.0(9.92)$ & $77.6(9.94)$ & $78.4(10.26)$ & $78.1(10.20)$ & $78.4(9.99)$ & $78.2(10.29)$ & $78.5(10.14)$ \\
\hline \multicolumn{10}{|l|}{ Women } \\
\hline No. of admissions & 6086 & 6537 & 6295 & 6814 & 6820 & 6820 & 6892 & 6569 & 6831 \\
\hline Age (mean; (SD)) & $80.3(8.59)$ & $80.5(8.64)$ & $80.9(8.61)$ & $80.7(8.72)$ & $81.3(8.49)$ & $81.2(8.46)$ & $81.2(8.47)$ & $81.5(8.30)$ & $81.8(8.41)$ \\
\hline
\end{tabular}


effect of the predictors [23]; for this study we were interested in the possible non-linear effect of time in the incidence rates. The GAMs were used in an exploratory manner [24] to identify visually the relationship of time to the mean incidence rate. For the cases where the smooth function of time was statistically significant, we fitted Generalized Linear Models (GLMs) to quantify formally changes in trends. For some models, the smooth non-parametric function was linear so we fitted a GLM with a linear relationship in time. In cases where the smooth function exhibited a turning point, we used piecewise regression with the identified turning points as the cut points, similar to what is described in chapter 12 of Faraway, 2006 [24].

We modeled the ASIR as a Gaussian random variable using year as an independent predictor. The GLM results consisted of a linear regression coefficient (the parameter of variable year), in this case the average increase/decrease (depending on the signal of the coefficient) in the rates by an increment of one year. For women, in order to evaluate how sales of anti-osteoporotic medication affect the ASIR, we fitted similar models using the number of packages sold as the independent variable.

We also conducted the analysis on the AR by gender using a GAM followed by a GLM to quantify statistically significant trends. In both cases we assumed that the incidence rates for each age and sex group have a different Poisson distribution, therefore for each group we explored a separate model. Whenever necessary, a negative binomial distribution was used to account for overdispersion [24]. For the AR trend analysis, the natural logarithm of the number of cases was modeled as function of year (nonparametric for GAM) and an offset factor of $\log$ (population size of each year). The results of the GLM were expressed as Incidence Rate Ratios (IRR), a relative risk measure representing the factor by which the rate increases/decreases with an increase of a year: a value lower than one represents a decrease in risk between one year and the next (decrease trend), a value higher than one represents an increased risk (increased trend), whereas an IRR equal to one represents an equal risk between two consecutive years (a steady trend). The relative estimated percentage change for each of the periods identified as having a statistically significant trend was calculated by dividing the difference between estimated rates in the final and initial year in the period by the estimated rate in the initial year of the period ([estimated rate final year-estimated rate initial year]/estimated rate initial year). For all measures we calculated the $95 \% \mathrm{Cl}$.

For the purposes of modeling the age and sex groups separately, the older age groups were aggregated so that the oldest group included patients over 79 years of age. This was done in order to avoid underdispersion.

Statistical analysis was performed using statistical software $\mathrm{R}$ version 2.14.1 (Project for Statistical Computing), the mgcv and MASS packages for trend analysis.

A simplistic version of the models implemented is:

(1) GAM models for ASIR rate $\sim \mathrm{s}$ (year) and rate $\sim \mathrm{s}$ (number of antiosteoporotic medication packages sold)

(2) GLM model for ASIR rate year and rate number of antiosteoporotic medication packages sold

(3) GAM models for AR $\log$ (cases) $\sim \mathrm{s}$ (year) $+\log$ (population)

(4) GLM models for AR $\log ($ cases $) \sim$ year $+\log$ (population)

\section{Results}

During the study period we identified 77,083 hip fractures, $77.4 \%$ in women (mean age (standard deviation (SD)) at admission 81.1 (SD 8.5) years old versus 78.3 (SD 10.1) and (p-value $<0.0001$ ) for women and men respectively. Table 1 shows number of admissions and mean age at admission, according to the year of admission whereas Table 2 shows the ASIR and age-specific rates during the period of study.
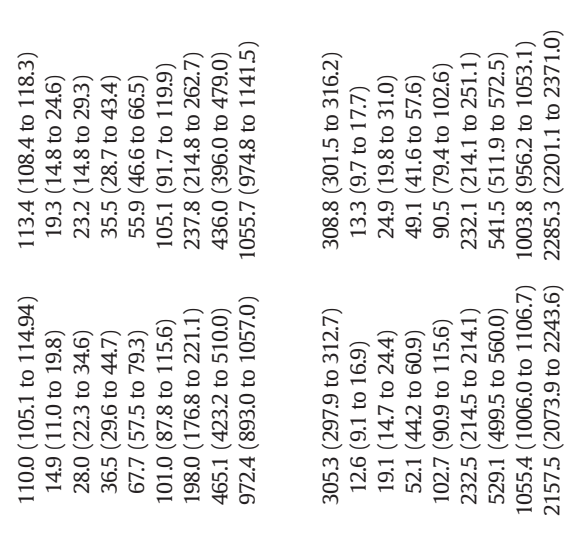

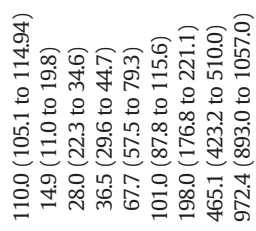

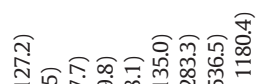

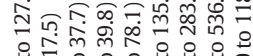

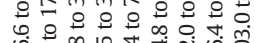

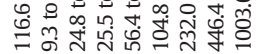

守宁

药

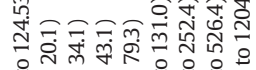

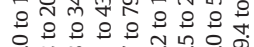

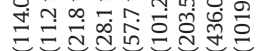

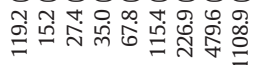
-

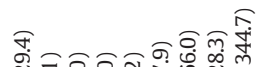

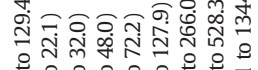

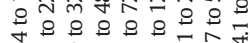

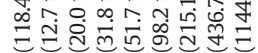

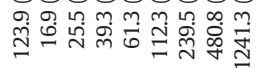

(2)

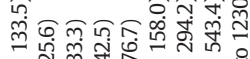

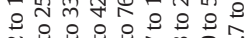

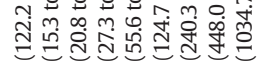

品

क.

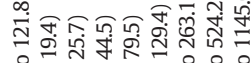
웅 त 0

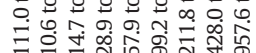

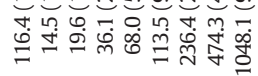

ํํำ

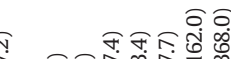

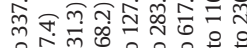

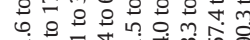

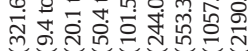

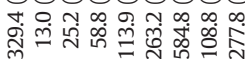

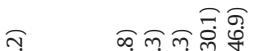

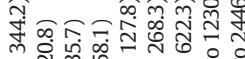

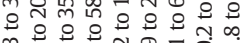

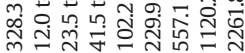
유ํ

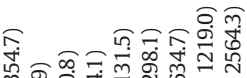
กे बำ $m$ 은

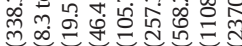

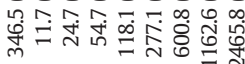

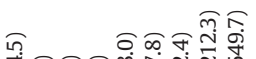

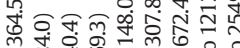

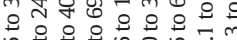

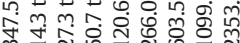
-

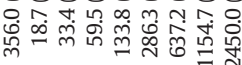

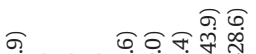

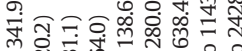

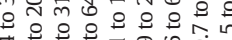

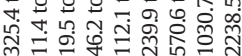

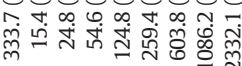
- $\bar{\infty}=\bar{m}$

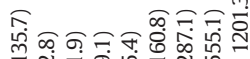
ปิ่

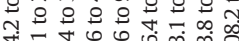

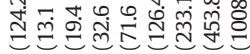

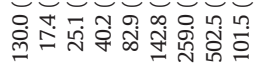

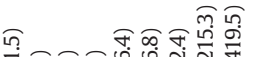

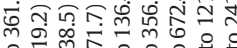

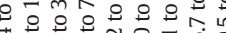

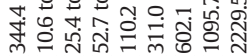

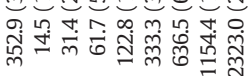

ซ

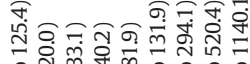
8 잉

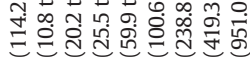

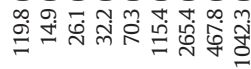

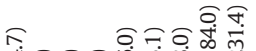

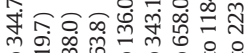

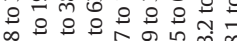

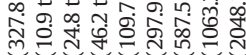
岗

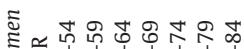

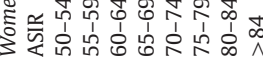


A

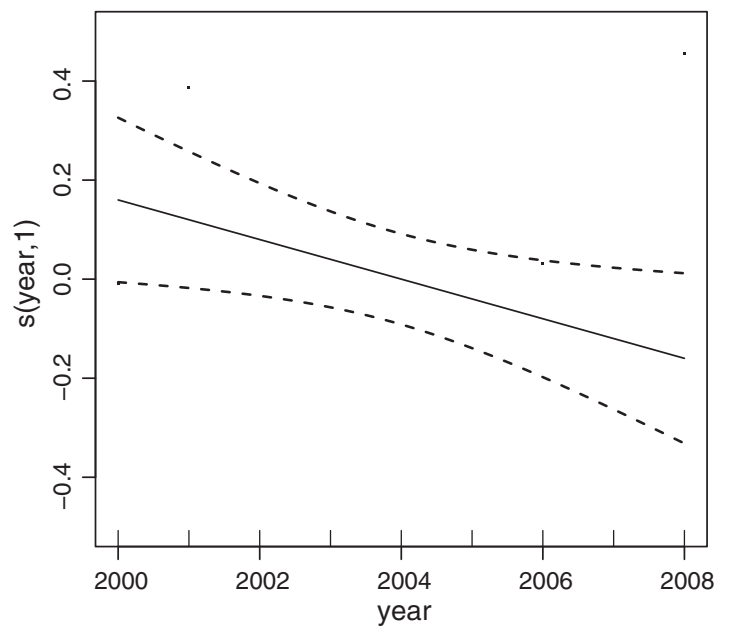

C

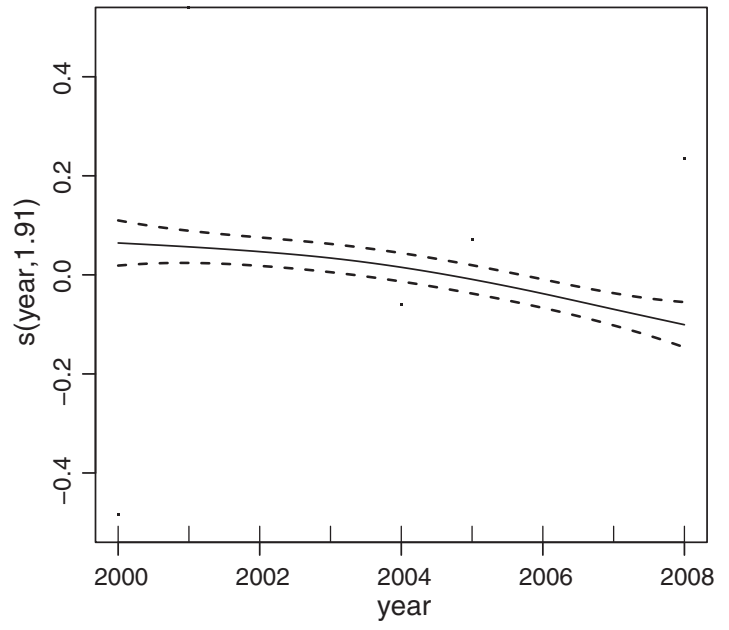

B

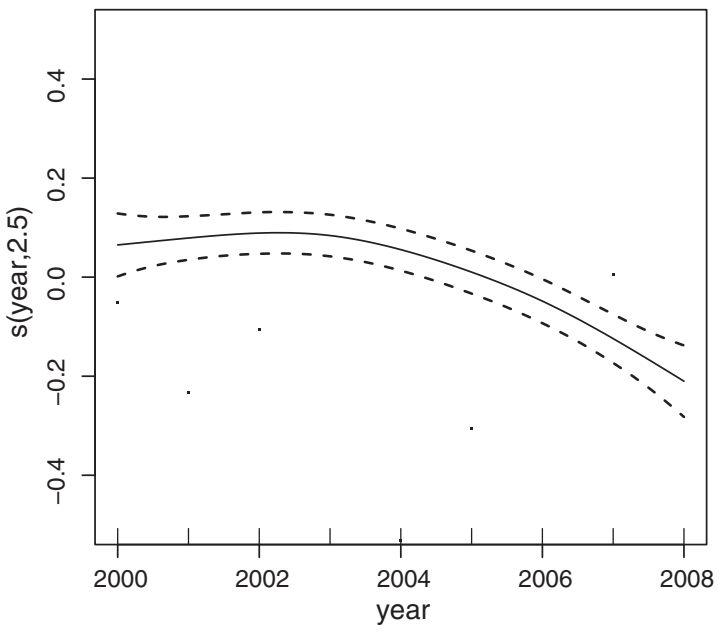

D

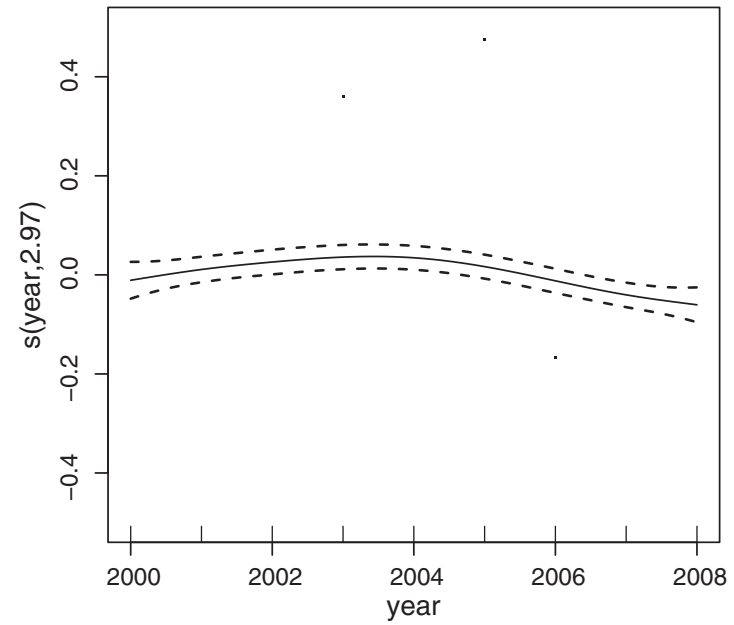

Fig. 1. Smooth function of time in AR for women aged: 55-59 years-old (panel A), 65-69 years-old (panel B), 75-79 years-old (panel C) and over 79 years-old (panel D).

The age groups where the smooth function of time was statistically significant, indicating a statistically significant trend of incidence rates according to time, were 55-59, 65-69, 70-74, 75-79 and over 79 years-old and over in women and 70-74 years-old in men. The following Figs. 1 and 2 show the statistically significant smooth functions of time by age groups in both sexes and in Table 3 we present the results for the age-specific rates using the quantification given by the GLM models.

We identified a linear effect of time in the age groups 55-59 for women and 70-74 for both genders (Figs. 1 and 2). For the other age groups in women, we identified a point within the period which determines a turn in the trend; these turning points are either increasing to decreasing or an alteration in the velocity of decrease. For women aged 65-69 and 75-79 years, 2003 can be visually identified from Fig. 1 as the year where a change occurred. For older women aged more than 79, we identified 2004 as the turning point in the trend.

In Fig. 3 it can be observed the evolution of anti-osteoporotic medication sales during the period of study. It can clearly be observed that after 2003 the number of biphosphonates packages is the major responsible for the total amount of anti-osteoporotic packages sold.
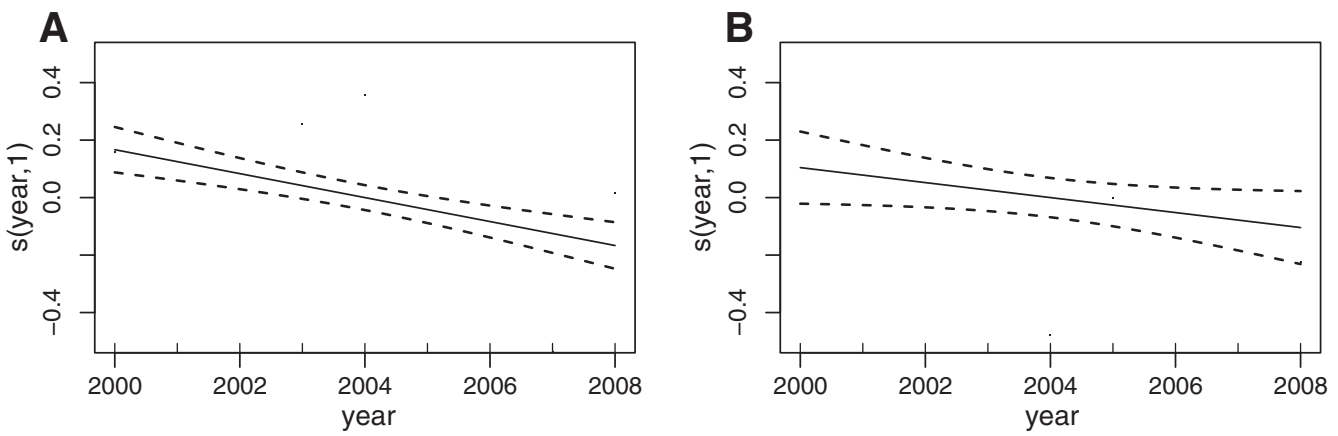

Fig. 2. Smooth function of time in AR for women aged 70-74 years-old (panel A) and for men aged 70-74 (panel B). 
Table 3

Incidence rate ratios (IRR), percentage relative change and corresponding 95\% CI calculated with GLM.

\begin{tabular}{|c|c|c|c|c|}
\hline Age-gender group & IRR (95\% CI) & & $\%$ Change $(95 \% \mathrm{CI})$ & \\
\hline Men & Period & & Period & \\
\hline $70-74$ & $\begin{array}{l}2000-2008 \\
0.974(0.952 \text { to } 0.997)\end{array}$ & & $\begin{array}{l}2000-2008 \\
-18.81(-32.56 \text { to }-2.25)\end{array}$ & \\
\hline Women & Period & & Period & \\
\hline $55-59$ & $\begin{array}{l}2000-2008 \\
0.961(0.932 \text { to } 0.991)\end{array}$ & & $\begin{array}{l}2000-2008 \\
-27.36(-43.18 \text { to }-7.18)\end{array}$ & \\
\hline $65-69$ & $\begin{array}{l}2000-2003 \\
1.027(0.986 \text { to } 1.070)\end{array}$ & $\begin{array}{l}2003-2008 \\
0.937(0.914 \text { to } 0.961)\end{array}$ & $\begin{array}{l}2000-2003 \\
8.28(-4.23 \text { to } 22.52)\end{array}$ & $\begin{array}{l}2003-2008 \\
-27.63(-36.21 \text { to }-17.94)\end{array}$ \\
\hline $70-74$ & $\begin{array}{l}2000-2008 \\
0.959(0.945 \text { to } 0.973)\end{array}$ & & $\begin{array}{l}2000-2008 \\
-28.36(-36.24 \text { to }-19.52)\end{array}$ & \\
\hline $75-79$ & $\begin{array}{l}2000-2003 \\
1.00(0.980 \text { to } 1.020)\end{array}$ & $\begin{array}{l}2003-2008 \\
0.968(0.957 \text { to } 0.981)\end{array}$ & $\begin{array}{l}2000-2003 \\
-0.48(-5.78 \text { to } 7.17)\end{array}$ & $\begin{array}{l}2003-2008 \\
-14.79(-19.89 \text { to }-9.38)\end{array}$ \\
\hline$>79$ & $\begin{array}{l}2000-2004 \\
1.013(1.005 \text { to } 1.023)\end{array}$ & $\begin{array}{l}2004-2008 \\
0.972(0.963 \text { to } 0.980)\end{array}$ & $\begin{array}{l}2000-2004 \\
5.71(1.98 \text { to } 9.58)\end{array}$ & $\begin{array}{l}2004-2008 \\
-10.86(-13.87 \text { to }-7.76)\end{array}$ \\
\hline
\end{tabular}

Analysis of the ASIR by gender revealed a statistically significant effect of time only among women (Fig. 4, panel A). This effect is non-linear and the year 2003 was identified as the turning point in the trend.

The linear model for the ASIR in women for the period 2000-2003 revealed that for each year, the incidence rate increased on average by 5.1 cases per 100,000 inhabitants with a $95 \% \mathrm{CI}(-1.6$ to 11.7$)$. As for the period 2003-2008, the decrease trend was statistically significant with an average decrease of 9.6 cases per 100,000 inhabitants with a $95 \% \mathrm{CI}(-13.4$ to -5.7$)$.

The non-linear effect of total number of anti-osteoporotic packages sold in ASIR (Fig. 4 panel B) is identical to that of time in ASIR (Fig. 4 panel A) with the same turning point identified in 2003. From 2003 the decrease of 10.2 cases per 100,000 inhabitants with 100,000 packages sold was statistically significant: $95 \% \mathrm{CI}(-15.7$ to -4.8$)$.

\section{Discussion}

In this population-based retrospective study, the year 2003 appeared as a turning point in the time trend of age-standardized incidence rate (ASIR) of hip fracture in women. The observed trend from 2000 to 2008 with a clear and abrupt decrease change in 2003 , is compatible with an intervention on national level. When analysing by sex, the anti-osteoporotic medication packages sold, in each of the years within the study period, had the same impact on the trend of ASIR for women, with the same turning point relating to 2003 sales.

After 2003, with the decrease of HRT, the total number of antiosteoporotic packages are manly bisphosphonates, suggesting that the massive increase in prescription of these medications was the intervention responsible for the change in the trends of ASIR. The rapidly increase of bisphosphonates sales can be the result of Bone and Joint Decade actions, that raised awareness to prevention, translating in a higher amount of individuals protected and consequently a decrease of incidence rates. However, in Portugal the number of patients treated cannot be assessed, as it is not possible to linkage different health related databases. Furthermore, the results by gender and age group are compatible with this hypothesis. The turning points were only present in women and the change was first observed in the age groups which are the target of these prescriptions in Portugal. Regardless of no causal relationship being able to be attributed is an ecological study, it acknowledges an important aspect that needs further clarification.

The existence of a turning point can be identified visually in other studies [9-11] where the change was attributed to bisphosphonates

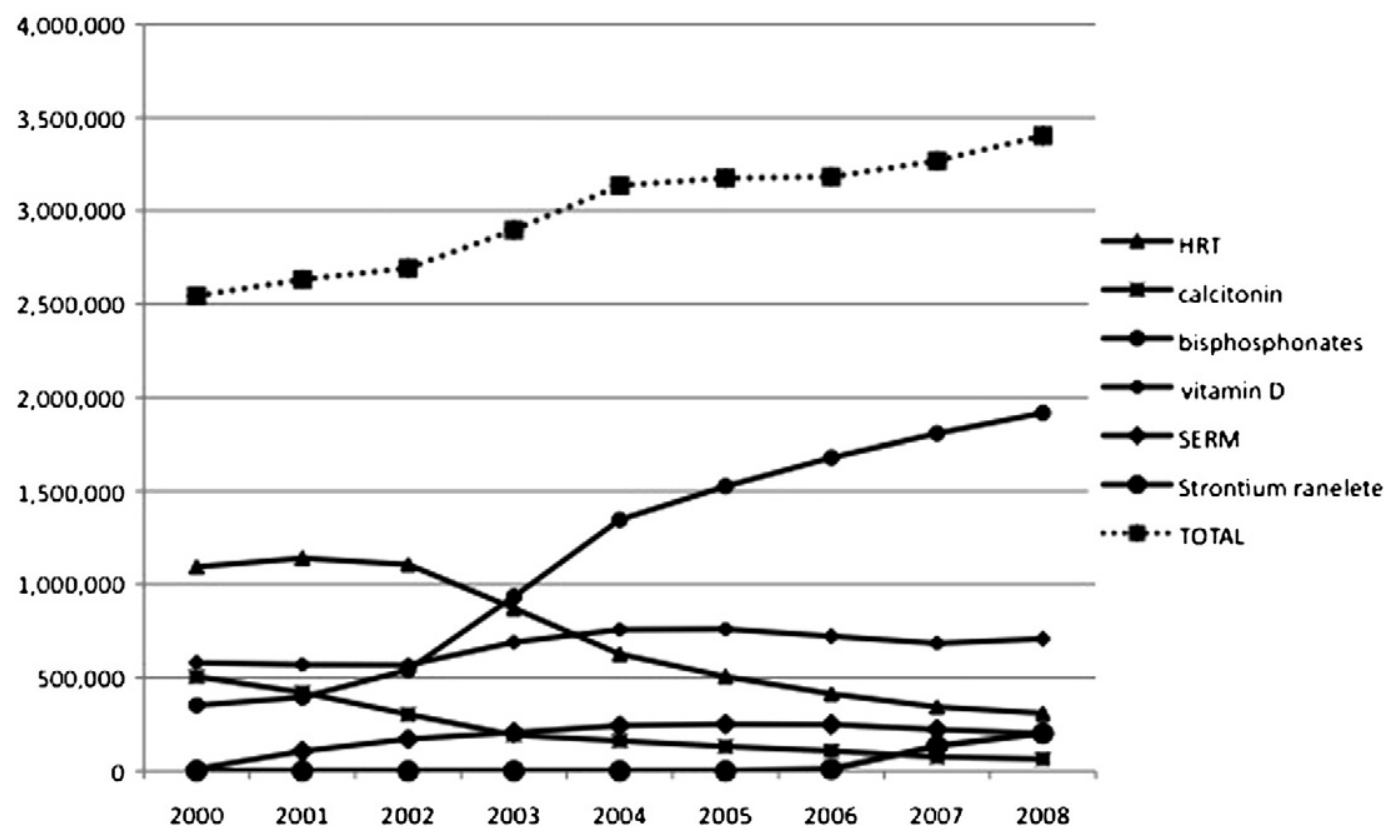

Fig. 3. Sales of medication for the prevention of osteoporosis and reduction of fracture risk in Portugal. 

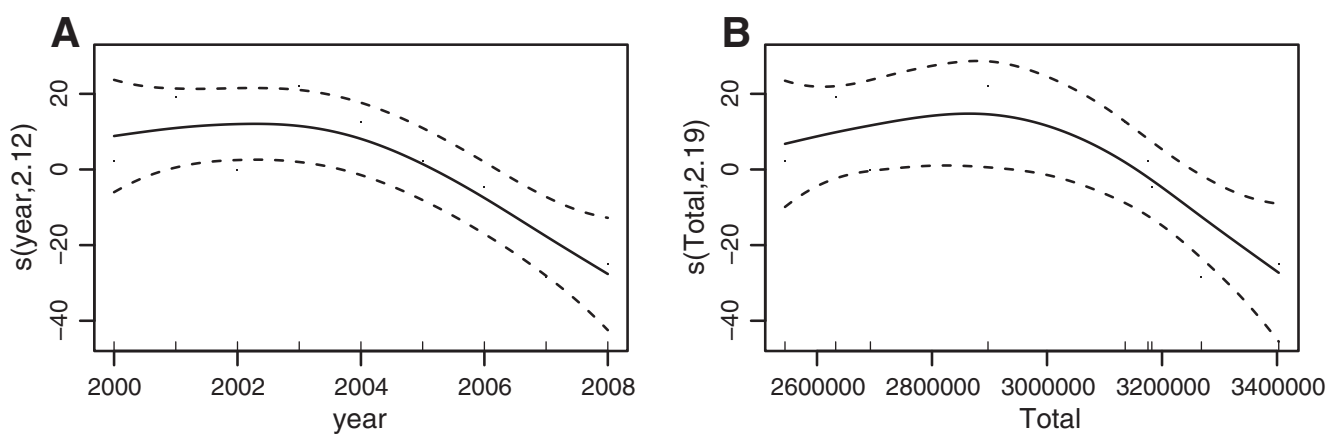

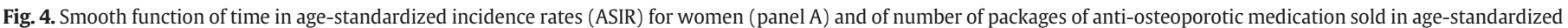
incidence rates (ASIR) for women (panel B).

$[10,11]$. However, when the trend is linear and present in both men and women [13-15] questions the extent of bisphosphonates influence were raised $[13,14]$. Results similar to ours were observed in a study from Australia [11] and a following study from the same population [10] showed that a decrease in bisphosphonates sales was followed by an increase of hip fracture incidence, underlying the possibility of the trends of hip fracture incidence rates being driven by bisphosphonates.

A change in the trend could be attributed to other factors, however it is unlikely that a change in the demographic and socioeconomic characteristics of the population could occur so promptly that impacted on hip fracture incidence so abruptly has our results pointed out. Other interventions, such as falls prevention campaigns, are usually focused on the elderly age groups (over 80 years old) and were not implemented nationwide in Portugal. Falls prevention actions in Portugal are sparse, conducted locally in some health centers (local impact) and they did not occur simultaneously, therefore it is not likely that such local actions would explain the accentuated turning points in the time trends of ASIR nationwide.

Our study has limitations that in our perspective do not invalidate the results. The relation between the number of bisphosphonates sold and age-standardized incidence rates for women can be questioned because no confounders were used to adjust the effect. In our opinion, the traditional risk factors for osteoporotic hip fractures that could be seen as confounders, such as socioeconomic status or cohort effect, would not have a sudden impact on ASIR, since they do not vary abruptly in time. In our study, the period of 9 years would not be long enough to observe major differences in traditional risk factors at ecological level and even so, they would not have an abrupt impact capable of a turning point in the time trends at national level, we would expect a continuous linear trend like the one obtained on 70-74 age group for both genders.

The strength of our study can be attributed to the data and the statistical methods applied. Our data covers a wide geographic scope, with data containing both hip fractures and medication sales on a national level (excluding the $5 \%$ of the population that lives in the autonomous regions), which overmatch local studies. In this paper we analyzed data from several perspectives using flexible models, which to our knowledge have not been used on epidemiological studies of hip fractures. These methods allowed the identification of non-linear effects, complemented with parametric models that allowed the quantification of the decreasing patterns, after the abrupt change. The trends of osteoporotic hip fractures require analysis not only of the age-standardized incidence rates by gender (which can hide unequal patterns by age groups) but also disaggregate analysis by age groups, since the risk increases exponentially with age and the population at risk may require differentiated care.

The incidence rates of hip fractures showed a decreasing trend with a well defined turning point in some age groups. Nevertheless the number of fractures is still raising and with the aging of the population this problem tends to be aggravated, increasing the costs of treatment and rehabilitation of patients. We identified trends of hip fractures at national level and these results may help making better decisions, it is important to have similar studies, in Portugal and other countries, in the following years to help understanding the role of anti-osteoporotic medication on hip fracture incidence, especially with the introduction of strontium ranelate that proved to have a positive impact on some parameters of hip structure, namely bone mineral density [25], but with inconclusive results regarding the decrease of hip fracture risk [26].

\section{Disclosure statement}

All authors declare no competing interest.

\section{Role of funding source}

The funder Foundation for Science and Technology has no role in this paper.

\section{Acknowledgements}

This work was financed byFEDER funds through the Programa Operacional Factores de Competitividade - COMPETE and by Portuguese funds through FCT - Fundação para a Ciência e a Tecnologia within the framework of the project PEst-C/SAU/LA0002/2011 and by PTDC/ SAU-EPI/113424/2009 grant and SFRH/BD/40978/2007 fellowship.

We would like to acknowledge the Central Administration of Health Services (ACSS) for the data from the National Hospital Discharge Register, and National Authority of Medicines and Health Products (INFARMED) for providing the data related to the sales of medication.

We would like also to acknowledge Carlos Alves (medical student) for the preparations of the database of hip fractures and participating in the exploratory data analysis, Lino Ministro (MD) for participating in the discussion and José Lopes (MD), medical doctor responsible for the codification of discharges registers from Hospital São João for answering some questions related to coding of data from the National Hospital Discharge Register.

\section{References}

[1] Cooper C, Cole ZA, Holroyd CR, Earl SC, Harvey NC, Dennison EM, et al. Secular trends in the incidence of hip and other osteoporotic fractures. Osteoporos Int 2011;22:1277-88.

[2] Nikitovic M,WodchisWP, Krahn MD, Cadarette SM. Direct health-care costs attributed to hip fractures among seniors: a matched cohort study. Osteoporos Int in press [Epub ahead of print].

[3] Ioannidis G, Flahive J, Pickard L, Papaioannou A, Chapurlat RD, Saag KG, et al. Non-hip, non-spine fractures drive healthcare utilization following a fracture: the Global Longitudinal Study of Osteoporosis in Women (GLOW). Osteoporos Int 2013;24:59-67.

[4] Sorensen HT, Sabroe S, Olsen J. A framework for evaluation of secondary data sources for epidemiological research. Int J Epidemiol 1996;25:435-42.

[5] Hulley SB, Cummings SR, Browner WS, Grady DG, Newman TB. Utilizing existing databases. Designing clinical research. 3rd ed. Philadelphia: Lippincott Williams \&Wilkins; 2007. p. 207-20. 
[6] Gomez-Cabello A, Ara I, Gonzalez-Aguero A, Casajus JA, Vicente-Rodriguez G. Effects of training on bone mass in older adults: a systematic review. Sports Med 2012;42: 301-25.

[7] Eurostat. Life expectancy at age 65, by gender; 2012.

[8] INE. Instituto Nacional de Estatística; 2012.

[9] Korhonen N, Niemi S, Parkkari J, Sievanen H, Palvanen M, Kannus P. Continuous decline in incidence of hip fracture: nationwide statistics from Finland between 1970 and 2010. Osteoporos Int in press [Epub ahead of print]

[10] Fisher A, Martin J, Srikusalanukul W, Davis M. Bisphosphonate use and hip fracture epidemiology: ecologic proof from the contrary. Clin Interv Aging 2010;5: 355-62.

[11] Fisher AA, O'Brien ED, Davis MW. Trends in hip fracture epidemiology in Australia: possible impact of bisphosphonates and hormone replacement therapy. Bone 2009;45:246-53.

[12] Hiligsmann M, Bruyere O, Roberfroid D, Dubois C, Parmentier Y, Carton J, et al. Trends in hip fracture incidence and in the prescription of antiosteoporosis medications during the same time period in Belgium (2000-2007). Arthritis Care Res (Hoboken) 2012;64:744-50.

[13] Abrahamsen B, Vestergaard P. Declining incidence of hip fractures and the extent of use of anti-osteoporotic therapy in Denmark 1997-2006. Osteoporos Int 2010;21: 373-80.

[14] Leslie WD, Sadatsafavi M, Lix LM, Azimaee M, Morin S, Metge CJ, et al. Secular decreases in fracture rates 1986-2006 for Manitoba, Canada: a population-based analysis. Osteoporos Int 2011;22:2137-43.

[15] Adams AL, Shi J, Takayanagi M, Dell RM, Funahashi TT, Jacobsen SJ. Ten-year hip fracture incidence rate trends in a large California population, 1997-2006. Osteoporos Int 2013;24:373-6.
[16] Arias LH, Treceno C, Garcia-Ortega P, Rodriguez-Paredes J, Escudero A, Sainz M, et al. Hip fracture rates and bisphosphonate consumption in Spain. An ecologic study. Eur J Clin Pharmacol in press [Epub ahead of print].

[17] ACSS. Auditoria da codificação clínica [Clinical codification Audits]; 2011.

[18] SPR, SPODOM. Recomendações para o Diagnóstico e Terapêutica da Osteoporose. Acta Reumatol Port 2007;32:49-59.

[19] DGS. Tratamento Farmacológico da Osteoporose Pós-menopaúsica. Lisboa; 2011

[20] Akesson K. New approaches to pharmacological treatment of osteoporosis. Bull World Health Organ 2003;81:657-64.

[21] Qaseem A, Snow V, Shekelle P, Hopkins Jr R, Forciea MA, Owens DK. Pharmacologic treatment of low bone density or osteoporosis to prevent fractures: a clinical practice guideline from the American College of Physicians. Ann Intern Med 2008;149:404-15.

[22] Morris JA, Gardner MJ. Epidemiological studies. In: Altman DG, Machin D, Bryant TN, Gardner MJ, editors. Statistics with Confidence. 2nd ed. Bristol: BMJ Books; 2000.

[23] Hastie T, Tibshirani R. Generalized additive models for medical research. Stat Methods Med Res 1995;4.

[24] Faraway JJ. Extending the linear model with R: generalized linear, mixed effects and nonparametric regression models. Boca Raton: Chapman \& Hall/CRC Taylor \& Francis Group; 2006.

[25] Briot K, Benhamou CL, Roux C. Hip cortical thickness assessment in postmenopausal women with osteoporosis and strontium ranelate effect on hip geometry. J Clin Densitom 2012;15:176-85.

[26] Freemantle N, Cooper C, Diez-Perez A, Gitlin M, Radcliffe H, Shepherd S, et al. Results of indirect and mixed treatment comparison of fracture efficacy for osteoporosis treatments: a meta-analysis. Osteoporos Int 2013;24:209-17. 